\title{
PARÂMETROS HIDROGEOLÓGICOS DO SISTEMA AQÜÍFERO BAURU NA REGIÃO DE ARAGUARI/MG: FUNDAMENTOS PARA A GESTÃO DO SISTEMA DE ABASTECIMENTO DE ÁGUA
}

\author{
LUIZ ANTÔNIO DE OLIVEIRA $\&$ JOSÉ ELOI GUIMARÃES CAMPOS ${ }^{2}$
}

\begin{abstract}
HYDROGEOLOGIC PARAMETERS OF THE BAURU AQUIFER SYSTEM IN THEARAGUARI REGION (STATE OF MINAS GERAIS): SUPPORT TO THE WATER SUPPLY ASSESSMENT The paper presents hydrogeologic parameters for the Bauru Aquifer System in the area of Araguari, state of Minas Gerais, Brazil. The public water supply system is based on groundwater exploration. It operates 96 deep wells responsible for a total water discharge up to $1900 \mathrm{~m}^{3} / \mathrm{h}$, resulting in an average yield of $19.5 \mathrm{~m}^{3} /$ h. The Bauru Aquifer System shows the following values for the dimensional parameters: the saturated thickness is 33 meters, the thickness of the vadose zone varies from 7 up to 36 meters, the effective porosity of the conglomerate facies is $19.5 \%$, the effective porosity of the sandy facies is $12.7 \%$, the hydraulic conductivity ranges from $5 \times 10^{-6}$ to $1.6 \times 10^{-4} \mathrm{~m} / \mathrm{s}$, with an average of $3.1 \times 10$ ${ }^{5} \mathrm{~m} / \mathrm{s}$, the average transmissivity is $9.6 \times 10^{-4} \mathrm{~m}^{2} / \mathrm{s}$, the average well discharge is $19.5 \mathrm{~m} / \mathrm{h}$, and the average specific capacity is $1.3 \mathrm{~m}^{3} /$ $\mathrm{h} / \mathrm{m}$. The wide variation of values results from the bad conditions of construction of the wells.
\end{abstract}

Keywords: Bauru Group, dimensional parameters, porous aquifer:

\begin{abstract}
Resumo O presente trabalho apresenta os valores de parâmetros hidrogeológicos levantados no Sistema Aqüífero Bauru na cidade de Araguari, estado de Minas Gerais. Na referida cidade o abastecimento público é feito por captação de água subterrânea. Este sistema conta com 96 poços, em operação, que em conjunto produzem uma vazão aproximada de $1900 \mathrm{~m}^{3}$ de água/hora, média de $19.5 \mathrm{~m}^{3}$ de água/hora/poço. O Sistema Aquífero apresenta os seguintes valores de parâmetros dimensionais: espessura saturada de 33 metros, espessura da zona vadosa variando de 7 a 36 metros, porosidade efetiva média de $15 \%$, condutividade hidráulica variando de $5 \times 10$ "a $1.6 \times 10^{-4} \mathrm{~m} / \mathrm{s}$. com média de $3,1 \times 10^{-5} \mathrm{~m} / \mathrm{s}$, transmissividade média de $9.6 \times 10^{-4} \mathrm{~m}^{2} / \mathrm{s}$, vazões médias de $19.5 \mathrm{~m}^{3} / \mathrm{h}$ e capacidade específica média de $1,3 \mathrm{~m}^{3} / \mathrm{h} / \mathrm{m}$. A disparidade entre os valores dos parâmetros levantados é reflexo das más condições de construção dos poços.
\end{abstract}

Palavras-chave: Grupo Bauru, parâmetros hidrogeológicos, aquífero intergranular.

INTRODUÇÃO A potencialidade de um aquíf́ero no que tange à sua reserva explotável e sua vazão de segurança está relacionada aos seus parâmetros hidrogeológicos, onde os mais importantes são representados pela porosidade total, porosidade efetiva, espessura saturada, condutividade hidráulica, transmissividade, coeficiente de armazenamento e capacidade específica. Essas grandezas descrevem as feições físicas e hidrodinâmicas dos aqüíferos, mas também são muito importantes para a sua adequada gestão, uma vez que são utilizados para as estimativas das taxas anuais de recarga (reservas renováveis), condições gerais de circulação subterrânea e vulnerabilidade do sistema à contaminação.

Em aquííferos não confinados e isotrópicos, os valores da transmissividade e da condutividade hidráulica são obtidos a partir de informações de ensaios de bombeamento. De acordo com Rebouças et al, (1999), para poços em que as informações de ensaios de bombeamento não são disponíveis, a determinação dos valores de transmissividade pode ser realizada através da análise dos valores de capacidade específica. Como a transmissividade é um valor diretamente proporcional à condutividade hidráulica, essa pode ser obtida diretamente.

O município de Araguari está localizado na região do Triângulo Mineiro, a 600 km de Belo Horizonte, 380 km de Brasília e 610 km de São Paulo. O município possui uma área total de $2.732 \mathrm{~km}^{2}$, IBGE (1996), dos quais 54 km² são ocupados pelo perímetro urbano, estando localizado entre as coordenadas geográficas de referência de $1^{\circ} 38^{\prime} \mathrm{S}$ e $18^{\circ} 44^{\prime} \mathrm{S}$, e $48^{\circ} 11^{\prime} \mathrm{W}$ e $47^{\circ} 15^{\prime} \mathrm{W}$ (figura I).
O abastecimento de água da população da cidade de Araguari (cerca de 100 mil habitantes) é feito exclusivamente por água subterrânea. O sistema de abastecimento é composto por 120 poços, 96 dos quais estão em operação, 21 inoperantes e 3 recém-perfurados ainda não foram incorporados ao sistema. Os 96 poços em funcionamento produzem uma vazão aproximada de $1.874 \mathrm{~m}^{3} /$ hora. Todos os poços pertencentes ao sistema público de abastecimento de água de Araguari exploram água do Sistema Aquiífero Bauru.

O objetivo do presente trabalho foi determinar os parâmetros hidrogeológicos de transmissividade, condutividade hidráulica e capacidade específica do Sistema Aqüúfero Bauru na região de Araguari/MG e analisar de forma comparativa os valores obtidos com aqueles levantados nos estudos hidrogeológicos de caracterização do Sistema Aquíifero Bauru no estado de São Paulo, desenvolvidos pelo DAAE - Departamento de Águas e Energia Elétrica do estado de São Paulo (1979). Os resultados serão utilizados para definir as diretrizes para gestão do sistema aquífero da região.

Os parâmetros hidrogeológicos do Sistema Aquíífero Bauru na região de Araguari/MG foram determinados por meio de ensaios de bombeamentos de poços tubulares profundos. A técnica de ensaio de bombeamento consiste em acompanhar por meio de medidas seqüenciais a vazão e o rebaixamento do nível da água no interior de um poço, num determinado tempo. Neste trabalho optou-se pelo ensaio de bombeamento de 24 horas, com vazão constante em alguns poços e vazão escalonada em outros de forma a 


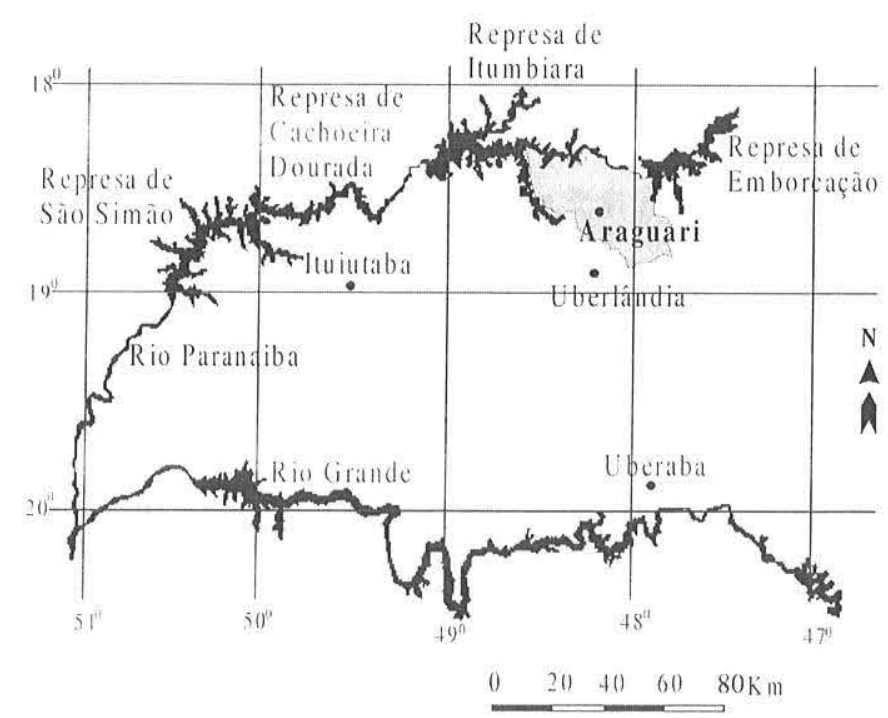

Figura I-Mapa de situação do Triângulo Mineiro com destaque para a localização do município de Araguari em Minas Gerais.

comparar as metodologias de tratamentos dos dados.

Os ensaios de bombeamento foram desenvolvidos em 17 poços, localizados em diversos pontos da área urbana de Araguari. Na tabela 1 estão descritos os locais de realização dos ensaios de bombeamento.

As medidas do nível de água foram obtidas usando-se medidor elétrico. Para determinação da vazão foi utilizado um tambor plástico de 200 litros de capacidade e um mangote plástico de 3 polegadas de diâmetro por 6 metros de comprimento conectado ao tubo ejetor do poço.

Os dados dos poços foram tratados em planilha eletrônica e no software Aquifer Test for windows 2.5 da Waterloo hydrogeologic Inc, utilizando o método de Newman para aquíferos não confinados. Posteriormente os dados foram submetidos a uma análise objetivando relacionar os valores de condutividade hidráulica, transmissividade, vazão e capacidade específica.

\section{CARACTERIZAČ̃̃O HIDROGEOLÓGICA DOMUNICÍPIO}

Os aquífferos estudados correspondem aos reservatórios subterrâneos vinculados ao Grupo Araxá, Formação Serra Geral e Grupo Bauru. De acordo com Oliveira (20)2), os aquíferos foram divididos conforme critérios geológicos e hidrodinâmicos em dois domínios: aquiíferos fraturados, formados pelos xistos do Grupo Araxá e pelos basaltos da Formação Serra Geral; e aquífero poroso, formado pelo conjunto latossolo, arenito friável e conglomerado do Membro Araguari, conjunto que representa a Formação Marília do Grupo Bauru e suas coberturas de regolitos (Fig. 2).

$\mathrm{O}$ aqüífero poroso é aqui denominado de Sistema Aquiúfero Bauru. O Grupo Bauru em toda a extensão do município comportase como aquíífero livre, com extensão lateral limitada pelos vales mais encaixados dos rios Araguari, Paranaíba e seus principais afluentes.

Em função de diferenças litológicas, de porosidade e de dinâmica da água em subsuperfície, o aquífero poroso foi dividido em dois subsistemas: Aquíifero Bauru Superior e Inferior (Oliveira 2002).

O Subsistema Bauru Superior é formado pelos solos profundos e pelas couraças lateríticas degradadas que em conjunto são
Tabela 1 - Locais de realização dos ensaios de bombeamento de poços.

\begin{tabular}{|c|c|c|c|}
\hline N"Poço & UTM & Altilude & : Localização \\
\hline$P 03$ & $0796806 / 7935281$ & 935 & Av Minas (jerais (1515. Agroatrat) \\
\hline$P 08$ & $0796162 / 7934026$ & 942 & Contingente \\
\hline PII & $0796921 / 7934795$ & $9+1$ & Praça Padre Elói (Jd Regina) \\
\hline P24 & $0796154 / 7938562$ & 9) 50 & R Walter Santiago, 920) (Panorama) \\
\hline P05 & $0796136 / 7939433$ & 9) 46 & Av Minas Gerais (2619) \\
\hline P45 & $0797826 / 7936491$ & 941 & Creche M arieta de Castro \\
\hline P47 & $0795115 / 7935358$ & 946 & UNIT \\
\hline P49 & $0794132 / 7938039$ & 952 & S. Sebastião (R. Palmeiras - Ceramica) \\
\hline P 48 & 079411117937368 & 952 & S. Sebastião (R. Palmeiras P. Bateria) \\
\hline P50 & $0794170 / 7938872$ & 9) 50 & Batro Vieno \\
\hline P5I & $0798628 / 7933184$ & 937 & Distrito Industrial \\
\hline$P C 05$ & $0794446.3 / 79355525$ & 1) 46 & Bateria de Chamcia \\
\hline PBOS & $0795912 / 79333817$ & 1) 42 & Bateria de Sĩo Benedito \\
\hline PKOI & $0793855 / 7935946$ & 946 & Bateria Cachoeirinha \\
\hline PKO2 & $0793876 / 7936999$ & 946 & Bateria Cachoeirinha \\
\hline PK03 & $0793807 / 7936018$ & 9) 46 & Bateria Cachoeirinha \\
\hline PK () 4 & $0793791 / 7935959$ & 946 & Bateria Cachoeirinha \\
\hline
\end{tabular}

classificados com latossolos. O Subsistema Bauru Inferior engloba os arenitos e conglomerados do Membro Araguari e corresponde à porção basal do aqüífero. O Sistema Aqüífero Bauru é o de maior potencial em fornecimento de água, concentrando mais de $90 \%$ dos poços responsáveis pelo abastecimento de água na região. No perímetro urbano de Araguari a totalidade dos poços que exploram água para o abastecimento público da população está locada neste domínio.

Os aquíf́eros fraturados englobam os basaltos da Formação Serra Geral, compondo o Sistema Aquífero Serra Geral (F1) e os xistos do Grupo Araxá, compondo o Sistema Aquífero Araxá (F2). A disponibilidade de água nos aqüíferos fraturados depende de aspectos estruturais relacionados à densidade da porosidade secundária planar, da orientação e interligação dessas estruturas, representadas principalmente por estruturas abertas como falhas, fraturas e zonas cataclásticas.

Quanto à ocorrência e à disponibilidade de água, o aquíffero fraturado é anisotrópico, heterogêneo e apresenta baixo potencial para abastecimento público, sendo que seu uso deve ficar restrito ao abastecimento de propriedades rurais e pequenas comunidades.

Com relação à capacidade de reservação e de fornecimento de água subterrânea o aquífero fraturado Serra Geral possui maior potencialidade que o Sistema Aquífero Araxá. Os poços perfurados nos xistos do Grupo Araxá apresentam vazões de 0 a $5.000 \mathrm{l} / \mathrm{h}$, enquanto os poços perfurados no basalto da Formação Serra Geral apresentam vazões de 0 a $50.000 \mathrm{l} / \mathrm{h}$.

O sucesso da locação de poços nos sistemas aquiíferos fraturados depende de levantamento geofísico prévio e de análises de lineamentos pela interpretação de imagens de satélite e de fotografias aéreas.

A rede de drenagem que corta a área de domínio dos aquíferos fraturados tem a maioria de suas nascentes localizadas no aqüífero poroso, acima da cota $880 \mathrm{~m}$, ou no contato do aqüífero poroso com os basaltos. As nascentes dentro do domínio fraturado são pouco expressivas e, em geral, apresentam baixas vazões. Casos de intermitência de fluxos ocorrem em drenagens que são alimentadas por águas do Sistema Aqüífero Araxá.

A concentração dos poços no Sistema Aquiúfero Bauru possi- 


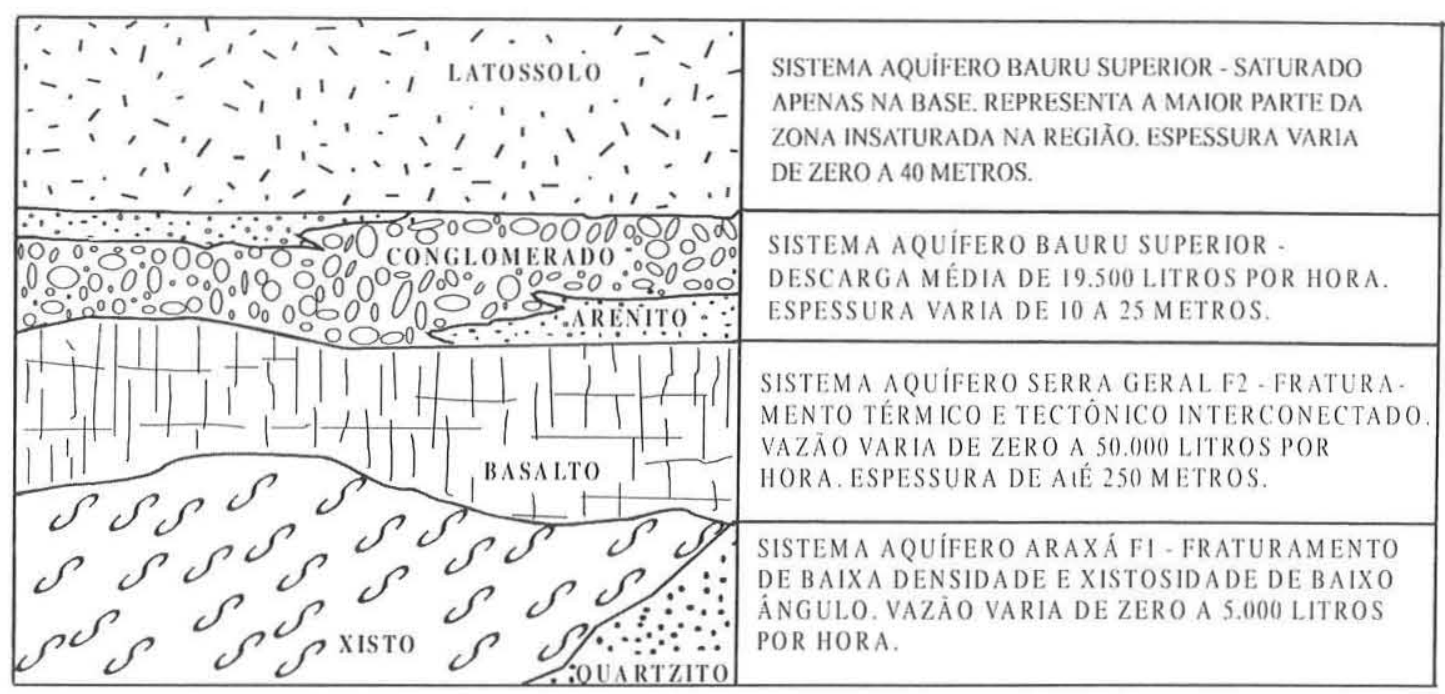

Figura 2 - Perfil lito-hidrogeológico da região de Araguari/MG.

bilitou um estudo mais detalhado deste aqüífero. As informações dos aquíf́eros fraturados referem-se somente a descrição geológica pontual dos aquíferos, bem como de informações qualitativas de poucos poços.

Sistema Aqüífero Araxá Os xistos, gnaisses e quartzitos micáceos do Grupo Araxá compreendem o embasamento da sucessão fanerozóica na área de estudos. Do ponto de vista hidrogeológico, são menos eficientes que os basaltos, no que tange ao armazenamento e fornecimento de água. A baixa densidade de fraturamento e a foliação em baixo ângulo dificultam a recarga, resultando no baixo potencial hidrogeológico.

$\mathrm{O}$ aquíf́ero não é muito explorado na região, e os poços perfurados apresentam baixas vazões, entre zero e $5 \mathrm{~m}^{3} / \mathrm{h}$, similares às observadas nas regiões de Goiânia e do Distrito Federal, (Campos \& Freitas Silva 1998).

Um poço com $150 \mathrm{~m}$ de profundidade localizado na escola municipal do Barracão (zona rural de Araguari) apresentou vazão de $2,5 \mathrm{~m}^{3} / \mathrm{h}$, transmissividade de $4,3 \times 10^{-1} \mathrm{~m}^{2} / \mathrm{min}$ e condutividade hidráulica de $5,2 \times 10^{-7} \mathrm{~m} / \mathrm{min}$. Os dados deste poço foram obtidos a partir de ensaio de bombeamento de 24 horas de duração.

Sistema Aqüífero Serra Geral As exposições de basaltos são pontuais e em geral, limitam-se às escarpas e bordas de chapada, razão pela qual, a recarga principal do aquífero Serra Geral se dá pela água infiltrada a partir do aquífero poroso.

Os basaltos por suas características litológicas e reológicas distinguem-se hidrogeologicamente das rochas de embasamento. As estruturas presentes nos topos de derrames como vesículas, amigdalas e superfícies entre derrames, quando interconectadas por fraturamentos podem armazenar grande quantidade de água. Além das estruturas tectônicas pós-derrames, há também o fraturamento térmico responsável por grande interconexão dos planos de diáclases e juntas.

Um poço existente, perfurado sobre lineamento estrutural utilizado para abastecimento da população do Distrito de Piracaíba município de Araguari / MG, locado com o auxílio de análise de fotografia aérea, apresenta vazão de $50 \mathrm{~m}^{3} / \mathrm{h}$, transmissividade de $1,4 \times 10^{-1} \mathrm{~m}^{2} / \mathrm{min}$, e condutividade hidráulica de $1,5 \times 10^{-3} \mathrm{~m} / \mathrm{min}$.
Por outro lado, dois poços existentes, situados em fazendas na localidade rural de Capim Branco, com profundidades de 200 e 80 $\mathrm{m}$, apresentaram vazões inferiores a $200 \mathrm{l} / \mathrm{h}$.

Sistema Aqüífero Bauru O Sistema Aquíffero Bauru compreende os depósitos não confinados de água subterrânea, associados a rochas da Formação Marília - Grupo Bauru e suas coberturas. Os sedimentos estão sobrepostos aos basaltos da Formação Serra Geral, acima da cota de 880 metros, e recobrem toda a área de chapada.

Apesar do caráter intergranular da porosidade, o Sistema Aqüífero Bauru é heterogêneo. As fácies que o compõem são distintas quanto à granulometria, porosidade, condutividade hidráulica e litotipo, e levaram à divisão do Sistema Aquíf́ero Bauru em dois subsistemas: Aquíf́fero Bauru Superior e Inferior.

O Aquífero Bauru Superior engloba os latossolos que formam espessas coberturas pedogenéticas desenvolvidas in situ. Os latossolos alcançam espessura máxima de $45 \mathrm{~m}$ e estendem-se acima da cota de $915 \mathrm{~m}$, compondo a porção superior deste subsistema. Na base dos latossolos pode ocorrer uma camada de couraça laterítica, em diferentes graus de degradação (pode conter concreções feruginosas).

Segundo a classificação pedológica (EMBRAPA 1999) os solos da região são classificados como latossolo vermelho distrófico e latossolo vermelho-amarelo distrófico.

Os solos apresentam variação granulométrica ao longo do perfil vertical. Em superfície e nas porções rasas, a maior atividade orgânica e estruturação resultam em uma textura média e condutividade hidráulica entre $10^{-4}$ e $10^{-6} \mathrm{~m} / \mathrm{s}$, coeficientes superiores àqueles medidos em profundidade. Abaixo do horizonte superficial e até a $15 \mathrm{~m}$ de profundidade, há incremento no teor de argila no solo, resultando na diminuição dos valores de condutividade hidráulica, que ficam na ordem de $10^{-6}$ e $10^{-7} \mathrm{~m} / \mathrm{s}$. Abaixo de $15 \mathrm{~m}$ de profundidade prevalecem os solos areno-siltosos, dominados por areia fina, textura média e condutividade hidráulica em torno de $10^{-6} \mathrm{~m} / \mathrm{s}$. A porosidade efetiva média nos latossolos foi de $12 \%$. Devido as suas condições de porosidade e de condutividade hidráulica, os latossolos assumem importante papel na recarga dos aquíferos poroso e fraturado. 
A camada rica em concreções caracteriza-se por material cascalhento em meio a matriz areno-argilosa, apesar de apresentarem condutividade hidráulica baixa, na ordem de $10^{-7} \mathrm{~m} /$ $\mathrm{s}$, a porosidade efetiva média medida foi de $13,5 \%$.

O Aquíífero Bauru Inferior é formado pelos sedimentos do Membro Araguari. As fácies arenítica e conglomerática do Membro Araguari estão assentadas discordantemente sobre os basaltos da Formação Serra Geral e compõem a base do Sistema Aquífero Bauru. Em função da paleogeografia irregular do topo do basalto, a espessura da camada deste subsistema é variável, podendo chegar a $20 \mathrm{~m}$. A camada está entre as cotas de 880 e $900 \mathrm{~m}$.

A fácies arenítica tem sua ocorrência localizada na região. Em geral, os arenitos encontram-se dispostos em blocos maciços de rocha cimentada por sílica e lateralmente passam para fácies intemperizadas e friáveis.

A fácies conglomerática é mal selecionada com seixos de diâmetros variando entre 2 a 350 mm de eixo maior, é clastosuportada e apresenta matriz arenosa a areno-argilosa. Mais de $90 \%$ dos seixos são compostos por quartzito com grau de arredondamento variável, friável ou litificado (silicificado), com características de retrabalhamento fluvial.

A camada de conglomerado é encontrada em toda a área de extensão do Sistema Aquiífero Bauru. Apesar da variação na espessura, o topo da camada é homogêneo, e comporta-se como uma superfície plana.

Exceto nas áreas marginais das chapadas, onde há adelgaçamento da camada por erosão, a fácies conglomerática encontra-se saturada de água, sendo que a porção não saturada do sistema ocorre sempre em materiais arenosos.

O Aqüífero Bauru Inferior é o principal aqüífero da região. A maioria das nascentes que alimentam as drenagens superficiais localiza-se na discordância entre os conglomerados e os basaltos.

RESULTADOSE DISCUSSÕES Os resultados obtidos a partir dos ensaios de bombeamento dos poços representam valores médios, visto que a água bombeada tem contribuição de toda a espessura saturada do aquíífero. Estes valores podem ainda sofrer interferências das condições construtivas do poço: posição dos filtros, granulometria do pré-filtro, diâmetro do revestimento, dentre outros.

Os valores de condutividade hidráulica, transmissividade, capacidade específica e vazão, levantados nos ensaios de bombeamento, estão sintetizados na Tabela 2.

Em $56 \%$ dos poços prevaleceram os valores de condutividade hidráulica $(\mathrm{K})$ da ordem de $10^{-5} \mathrm{~m} / \mathrm{s}$, medidos nos poços das baterias Cachoeirinha (PK01, 02, (03 e 04) Chamcia (PC05), São Sebastião (P48 e P49), e nos poços isolados do Jardim Regina (P1 1), Panorama (P24) e Vieno (P50). Os valores mais baixos de condutividade hidráulica da ordem de $10^{-6} \mathrm{~m} / \mathrm{s}$, foram determinados em $33 \%$ dos poços: poço PB5 da bateria de poços São Benedito, poço da Creche Marieta de Castro (P45), Industrial (P51) e ambos os poços da Av. Minas Gerais (P03 e P05). Apenas dois poços, UNIT (P47) e Contingente $(\mathrm{P}(0))$ apresentaram condutividade hidráulica na faixa de $10^{-4} \mathrm{~m} / \mathrm{s}$.

A transmissividade (T) média medida nos poços foi de $9,1 \times 10^{-4}$ $\mathrm{m}^{2} / \mathrm{s}$. Em $78 \%$ dos poços os valores de transmissividade ficaram na faixa de $10^{-4} \mathrm{~m}^{2} / \mathrm{s}$, correspondendo aos poços $\mathrm{PB} 05$ da bateria de poços São Benedito, Cachoeirinha (PK 01, 02, 03 e 04), São Sebastião (P48 e 49) e Chamcia (PC05), e aos poços isolados localizados na Av. Minas Gerais (P03 e 05), creche Marieta de Castro (P45), Industrial (P51), Vieno (P50) e Jardim Regina (P11).
Os maiores valores de transmissividade, na ordem de grandeza de $10^{-3} \mathrm{~m}^{2} / \mathrm{s}$, ocorreram nos poços da UNIT (P47), Contingente (P08) e Panorama (P24).

A capacidade específica (Cs) média dos poços foi de $1,3 \mathrm{~m}^{3} / \mathrm{h} / \mathrm{m}$. Valores de capacidade específica superiores a 2 foram determinados nos poços do Vieno (P50), Contingente (P08) e Cachoeirinha (PK01). Os valores mais baixos de capacidade específica, da ordem de $10^{-1} \mathrm{~m}^{3} / \mathrm{h} / \mathrm{m}$, foram levantados nos poços UNIT (P47), Av. Minas Gerais (P03 e P05), Industrial (P5I), Panorama (P24), São Benedito (PB05), Jardim Regina (PI1). A variação dos valores de capacidade específica é diretamente relacionada à espessura da fácies conglomerática interceptada pelo poço.

A vazão $(Q)$ média medida foi de $2,7 \times 10^{4} \mathrm{~m}^{3} / \mathrm{h}$. O poço do bairro Vieno (P50) apresentou a maior vazão, com $80 \mathrm{~m}^{3} / \mathrm{h}$, enquanto que o poço da Av. Minas Gerais (P05) foi o de menor vazão, com $9,5 \mathrm{~m}^{3} / \mathrm{h}$. A análise dos valores demonstra que as maiores vazões estão relacionadas aos poços locados em latossolo vermelhoamarelo na região que abrange os bairros São Sebastião e Vieno. Esta classe de latossolo por apresentar textura arenosa e maior condutividade hidráulica favorecem as condições de recarga e circulação, o que resulta na maior vazão média dos poços construídos sobre sua área de ocorrência.

Objetivando estabelecer uma relação entre os poços estudados, os valores referentes à condutividade hidráulica, transmissividade, coeficiente de armazenamento, capacidade específica e vazão foram plotados em gráfico de linhas, o que permite fazer uma analogia direta dos resultados (Fig. 3).

Por serem parâmetros diretamente proporcionais, definidos pela equação $\mathrm{T}=\mathrm{K} \times \mathrm{b}$, justifica-se a relação entre os valores de $\mathrm{K}$ e T (figura 3). O comportamento das linhas do gráfico demonstra relação entre os valores de Cs e Q nos poços Panorama (P24), Cachoeirinha (PK 01, 02, (03 e 04), Vieno (P50), Industrial (P51) e São Benedito (PB05).

Relacionando os valores de cada parâmetro com os diversos pontos de realização dos ensaios de bombeamento, observa-se que o intervalo de variação de T, K e Q é grande, entretanto, fica

Tabela 2 - Síntese dos resultados de K, T, Cs e Q obtidos nos ensaios de bombeamento em poços locados no Sistema Acjüífero Bauru, perímetro urbano de Araguari/MG.

\begin{tabular}{|c|c|c|c|c|}
\hline Local & $\begin{array}{c}\mathrm{K} \\
(\mathrm{m} / \mathrm{s})\end{array}$ & $\begin{array}{c}\mathrm{T} \\
\left(\mathrm{m}^{2} / \mathrm{s}\right)\end{array}$ & $\begin{array}{c}\text { Cs } \\
\left(\mathrm{m}^{3} / \mathrm{h} / \mathrm{m}\right)\end{array}$ & $\begin{array}{c}Q \\
\left(\mathrm{~m}^{3} / \mathrm{h}\right)\end{array}$ \\
\hline Av. Minas Gerais P(0)5 & $5.0 \times 10^{6}$ & $1.6 \times 10^{-1}$ & $0.6(29)$ & $9.47 \times 100^{3}$ \\
\hline Av. Minas Gerais P03 & $6.8 \times 10^{6}$ & $3,0 \times 10^{-4}$ & 0.673 & $1.36 \times 10)^{4}$ \\
\hline Vieno P50 & $1,0 \times 10^{-5}$ & $3.9 \times 10^{-4}$ & 2,64 & $8 \times 10^{4}$ \\
\hline UNIT P47 & $1.0 \times 10^{-4}$ & $3.5 \times 10^{-3}$ & 0.46 .5 & $1,(0) \times 1\left(0^{4}\right.$ \\
\hline Cachoeirinha PKI & $1.3 \times 10^{-5}$ & $5,3 \times 10^{-4}$ & 2,143 & $3,0 \times 10^{4}$ \\
\hline Cachoeirinha PK2 & $1,6 \times 10^{-5}$ & $5,4 \times 10^{-4}$ & 1.513 & $2.80 \times 100^{-1}$ \\
\hline Cachoeirinha PK3 & $1.2 \times 10^{-5}$ & $4.9 \times 10^{-4}$ & 1,333 & 2.4()$\times 10^{4}$ \\
\hline Cachoeirinha PK4 & $1,4 \times 10^{-5}$ & $5,5 \times 10^{-4}$ & 1,67 & $3.00 \times 100^{-4}$ \\
\hline Contingente $\mathrm{P}(08$ & $1,6 \times 10^{-4}$ & $3,1 \times 10^{-3}$ & 2.407 & $1.42 \times 100^{4}$ \\
\hline Industrial P5I & $8,9 \times 10^{-6}$ & $3,9 \times 10^{-4}$ & $(0.689$ & $2,48 \times 1()^{4}$ \\
\hline Panorama P24 & $8.9 \times 10^{-5}$ & $3.5 \times 10^{-3}$ & 0.717 & $1.62 \times 100^{4}$ \\
\hline Jardim Regina PII & $1.2 \times 10^{-5}$ & $3.7 \times 10^{-4}$ & 0,991 & $2.30 \times 10^{4}$ \\
\hline São Benedito PB(05 & $5,9 \times 10^{-6}$ & $2.1 \times 10^{-4}$ & 0.808 & $9,72 \times 10^{3}$ \\
\hline São Sebastião.P48 & $1,5 \times 10^{.5}$ & $6,2 \times 10^{-4}$ & 1,041 & $3,80 \times 100^{4}$ \\
\hline São Sebastião.P49 & $1,8 \times 10^{-5}$ & $9,5 \times 10^{-4}$ & 1,348 & $6,00 \times 10^{4}$ \\
\hline Creche M. de Castro P45 & $9,0 \times 10^{-6}$ & $3.2 \times 10^{-4}$ & 0.898 & $2,30 \times 10^{4}$ \\
\hline Chamcia PC05 & $1.1 \times 10^{-5}$ & $3,8 \times 10^{-4}$ & 1,309 & $2,50 \times 10^{4}$ \\
\hline TOTAL & $5,27 \times 10^{-4}$ & $1,64 \times 10^{-2}$ & 22,1 & $4,59 \times 10^{5}$ \\
\hline MÉDIA & $3,10 \times 10^{-5}$ & $9,64 \times 10^{-4}$ & 1,30 & $2,70 \times 10^{4}$ \\
\hline MEDIANA & $1,28 \times 10^{-5}$ & $4,97 \times 10^{-4}$ & 1,31 & $2,40 \times 10^{4}$ \\
\hline MÍNIMO & $5,03 \times 10^{-6}$ & $1,61 \times 10^{-4}$ & $6,09 \times 10^{-1}$ & $9,47 \times 1\left(0^{3}\right.$ \\
\hline
\end{tabular}


clara a predominância de valores mais altos de $\mathrm{T}, \mathrm{K}$ nos poços UNIT (P47), Panorama (P24) e Contingente (P08). Ao contrário do que ocorre com os valores de $\mathrm{K}$ e T, há um equilíbrio dos valores de Cs dos poços, representados na figura 3 por uma reta horizontal.

De posse dos parâmetros hidrodinâmicos e dimensionais do Sistema Aquíffero Bauru na região de Araguari, foram estimadas as reservas hídricas na área urbana. Para as estimativas foi considerada uma área circular eliminando-se apenas as faixas de afloramento dos basaltos o que resultou em 45,6 km² (Fig. 4). A escolha da área foi baseada na poligonal regular que inclui a maior parte da área onde há bombeamento. A porção da área que ocupa zonas não urbanas, deve ser considerada uma vez que os cones de depressão se desenvolvem para fora do limite da cidade e, na prática, há um volume de água disponível nas adjacências da área de exploração.

Os volumes estabelecidos são de $1,7 \times 10^{6} \mathrm{~m}^{3} / \mathrm{ano} ; 2,4 \times 10^{8} \mathrm{~m}^{3}$ e $4,1 \times 10^{6} \mathrm{~m}^{3} / \mathrm{ano}$, respectivamente para as reservas renováveis, permanentes e explotáveis. Para efeito do cálculo das reservas explotáveis foi considerado o volume de água referente à reserva renovável mais $10 \%$ da reserva permanente, o que é compatível com um sistema não confinado, com excelentes condições de recarga e circulação. A retirada de $10 \%$ da reversa permanente não compromete o aquíf́fero pois o gradiente gerado pelo rebaixamento regional cria condiçôes para uma recarga adicional.

Considerando que a população de 100 mil habitantes atendida pelo sistema público de abastecimento utilize um volume per capita similar à média nacional (250 litros por habitante dia para pessoas de condições socioeconômicas similares as de Araguari), concluise que os poços exploram o dobro do volume necessário para seu atendimento, onerando os custos com energia elétrica e consumo de bombas. O excedente é perdido por vazamentos na rede adutora de distribuição.

O abastecimento eficiente atual e futuro da cidade de Araguari requer uma gestão adequada do sistema aquíffero e deverá incluir uma série de práticas e iniciativas para garantir a possibilidade de

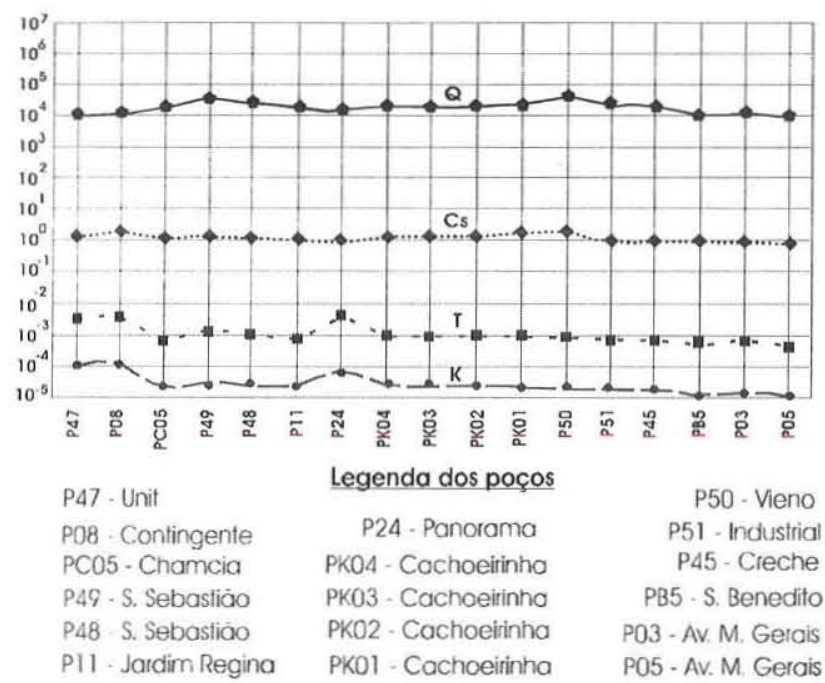

Figura 3 - Gráfico comparativo dos valores $K(\mathrm{~m} / \mathrm{s}), T\left(\mathrm{~m}^{2} / \mathrm{s}\right)$, Cs $\left(\mathrm{m}^{3} / \mathrm{h} / \mathrm{m}\right)$ e $Q\left(\mathrm{~m}^{3} / \mathrm{h}\right)$ para o Sistema Aqüífero Bauru na região de Araguari $M G$. crescimento da população atendida e do eventual aumento da demanda para a economia local. Dentre as principais práticas destacam-se:

- construção adequada dos sistemas de captação, segundo as normas técnicas, para minimizar os riscos de contaminação e maximizar a produção de cada poço individualmente. A definição dos perímetros de proteção dos poços também é fundamental;

- aumento da capacidade dos reservatórios em superfície, para evitar os frequientes problemas de desabastecimento e rompimento de adutoras pela sobre-pressão na rede;

- efetivar a prática da cobrança pelo volume efetivamente consumido, para dar conotação econômica a água e evitar os desperdícios comumente observados na região. A prática da cobrança deve incidir desde o DEMAE (Departamento Municipal de Água e Esgoto) até os consumidores domésticos e industriais;

- coleta e tratamento dos efluentes, evitando a disposição das águas servidas in situ, o que é incompatível em uma área onde o abastecimento é baseado em mananciais subterrâneos, especialmente sobre aquíf́eros não confinados;

- desenvolvimento de práticas de recarga artificial dos aquíferos, para compensar a diminuição da infiltração natural pela impermeabilização em função da urbanização. As condições físicas (relevo, tipos de solos, espessura da zona vadosa) na região de Araguari favorecem a aplicação da metodologia desenvolvida no Distrito Federal (Cadamuro et al. 2002) e

- desenvolvimento de um programa de monitoramento para avaliação contínua do comportamento dos níveis d'água. Sugerese que sistemas de automação sejam instalados em poços estrategicamente distribuídos para monitorar o sistema como um todo.
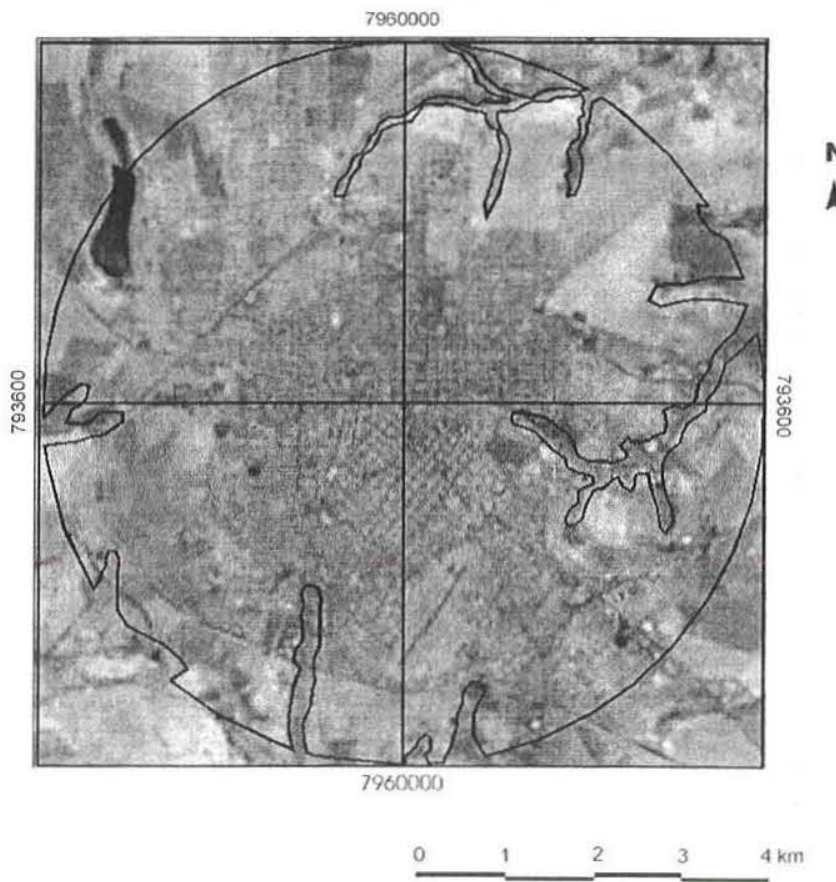

Figura 4 - Limite da área utilizada para os cálculos das reservas hídricas do Sistema Aqüífero Bauru na região de Araguari. Notar que a área dos vales das drenagens que fluem sobre basaltos foi eliminada. 
CONCLUSÕES Dos três sistemas aquííferos presentes na região de Araguari, apenas o Sistema Bauru apresenta potencial para abastecimento público da cidade. Os sistemas fraturados Serra Geral e Araxá tem potencial limitado e devem ser utilizados para suprir demandas isoladas e mais restritas (abastecimento de pequenas comunidades, clubes, pequenas indústrias, etc).

Em se tratando de aqüífero poroso (relativamente isotrópico e homogêneo), uma maior correlação entre os valores levantados dos parâmetros hidrogeológicos do Sistema Aquífero Bauru era esperada. A disparidade dos resultados evidencia falhas nos aspectos técnico-construtivos dos poços, como mau dimensionamento da granulometria do pré-filtro, abertura inadequada dos filtros, coluna insuficiente de filtros, bombas mal dimensionadas, diâmetro insuficiente do espaço anelar para posicionamento do pré-filtro, dentre outros.

A avaliação da potencialidade aquíf́era do Sistema Aqüífero Bauru, utilizando-se a distribuição espacial dos parâmetros hidrogeológicos, somente foi possível pela análise dos valores de vazão e de capacidade específica.

Os valores superiores dos parâmetros hidrogeológicos do Sistema Aqüífero Bauru na região de Araguari/MG, quando comparados aos valores levantados por Azevedo et al (1999) no Sistema Aquíffero Bauru no estado de São Paulo (Tabela 3), demonstram maior potencialidade do aqüífero na região de Araguari. Este fato é decorrente do grande volume de conglomerados clasto-suportados presente na região de Araguari e ausente nas demais áreas de ocorrência do Grupo Bauru.

Em virtude de vazamentos na rede adutora atualmente o sistema de poços explora o dobro da vazão necessária. Como a vazão excedente retorna ao sistema aquífero na forma de recarga artificial, o maior impacto desse fato é o consumo demasiado em energia elétrica e em manutenção de bombas, por outro lado, também há risco efetivo de contaminação das águas na rede de distribuição.

Agradecimentos Aos revisoresda RBG pelas sugestões ao manuscrito.

Tabela 3 - Comparação entre os valores dos parâmetros hidrogeológicos do Sistema Aquiífero Bauru na região de Araguari/MG e os levantados no estado de São Paulo.

\begin{tabular}{lccc}
\hline \multicolumn{4}{c}{ ESTADO DE SÃO PAULO } \\
\hline Parâmetro & $\mathrm{Q} \mathrm{m} \mathrm{m}^{3} / \mathrm{h} / \mathrm{m}$ & $\mathrm{Q} \mathrm{m}^{3} / \mathrm{h}$ & $\mathrm{T} \mathrm{m}^{2} / \mathrm{d}$ \\
\hline Média & 0,80 & 18,4 & 42,6 \\
Mediana & 0,38 & 12,3 & 16,1 \\
Mínima & 0,004 & 0,2 & 1,1 \\
Máximo & 8,93 & 150 & 437 \\
\hline \multicolumn{4}{c}{ REGIÃO DE ARAGUARI/MG } \\
\hline Média & 1,30 & 27 & 83,28 \\
Mediana & 1,31 & 24 & 42,94 \\
Mínima & 0,609 & 9,5 & 13.91 \\
Máximo & 2,65 & 80 & 302 \\
\hline
\end{tabular}

\section{Referências}

Azevedo A.A.B., Iritani M.A., Oda G.H., Kakazu M.C., Campos J.E., Ferreira L.M.R., Silveira E.L. 1999. Zoneamento das características hidrodinâmicas (transmissividade e capacidade específica) do Sistema Aquífero Bauru no estado de São Paulo - Brasil. In: I Joint World Congress on Groundwater. ABAS, Fortaleza. CD ROM.

Cadamuro A.L.M. 2002. Proposta, avaliação e aplicabilidade de técnicas de recarga artificial em aquiíferos fraturados para condomínios residenciais do Distrito Federal. Dissertação de Mestrado, Instituto de Geociências, Universidade de Brasília, 126p.

Campos J.E.G. \& Freitas-Silva F.H. 1998. Hidrogeologia do Distrito Federal. In: IEMA/SEMATEC/UnB 1998. Inventário Hidrogeológico e dos Recursos Hídricos Superficiais do Distrito Federal. IEMA/SEMATEC/UnB. Brasília. Vol. 4, 234p.

DAAE - Departamento de Águas e Energia Elétrica. 1979. Estudo de águas subterrâneas, Regiões Administrativas 10 e 11, Presidente Prudente e Marília, São Paulo. 3 Vol.

EMBRAPA - Empresa Brasileira de Pesquisas Agropecuárias. 1999.
Sistema Brasileiro de Classificação de Solo. Centro Nacional de Pesquisa de Solos. Rio de Janeiro, 412 pp.

IBGE - Instituto Brasileiro de Geografia e Estatística. 1996. Anuário estatístico. Rio de Janeiro.

Oliveira L.A. 2002. O Sistema Acü̈́fero Bauru na Região de Araguari/ MG: propostas de gestão e parâmetros dimensionais. Dissertação de Mestrado, Instituto de Geociências, Universidade de Brasília, $120 \mathrm{p}$.

Rebouças A.C., Iritani M.A., Hassuda S., Souza J.C.S. 1999. Avaliação dos valores de transmissividade do aquífero sedimentar no município de Caçapava (SP), com base na capacidade específica obtida em testes de bombeamento. In: I Joint World Congress on Groundwater. ABAS, Fortaleza. CD ROM.

Manuscrito A-1401

Recebido em 07 de janeiro de 2003

Revisão dos autores em 05 de março de 2004 Revisão aceita em 15 de março de 2004 